\title{
Obstrüktif Uyku Apne Sendromunda Görülen Hipoksinin İşitsel Beyin Sapı Cevabına Etkileri
}

\author{
The Effects of Hypoxiatothe Auditory Brainstem Responsewhich is \\ Seen in the Obstructive Sleep Apnea Syndrome \\ Yasin YAĞIZ, Yücel TANYERI, Selma YILAR
}

Ondokuz Mayıs Üniversitesi Tıp Fakültesi,Kulak Burun Boğaz Hastalıkları AD, Samsun

Geliş Tarihi / Received: 08.12.2013

Kabul Tarihi / Accepted: 09.12.2013

\section{ÖZET}

Amaç: Obstrüktif uyku apnesendromlu hastalarda meydana gelen hipoksinin işitsel beyin sapı cevabı üzerine olan etkilerinin araştırılmasıdır.

Gereç ve Yöntem: Basit horlama tanısı almış 10 kişiden oluşan kontrol grubu ile obstrüktif uyku apnesendromlu 31 kişiden oluşan 3 ayrı hasta grubunun beyin sapı odyometri sonuçları karşılaştirılmıştır.

Bulgular: Kontrol grubu ile hasta grupları arasında I., III., V. dalga latans ve dalgalar arası latans değerleri için istatistiksel analiz yapıldı. Hafif obstrüktif uyku apnesendromlu grupta bu değerler için anlamlı farklılık olmadığı tespit edildi. Dalga III latansının, orta obstrüktif uyku apnesendromlu grupta, I., III., V. dalga latans ve I-III dalgalar arası latans değerlerinin şiddetli obstrüktif uyku apne sendromlu grupta anlamlı derecede uzamış olduğu tespit edildi. Hastaların uyku sırasında ölçülen oksijen satürasyonlarının \%80'in altında kaldığı sürenin toplam uyku süresine oranı incelendi. Bu oranın şiddetli obstrüktif uyku apnesendromlu hasta grubunda diğer hasta gruplarına göre anlamlı derecede daha yüksek olduğu tespit edildi.

Sonuç: Dalga III latansı kaynağı olan koklearnukleus nöronlarının diğer dalga kaynaklarına göre hipoksiye daha fazla duyarlı olabileceği düşünüldü. Beyin sapı odyometrisi sonuçlarının özellikle şiddetli obstrüktif uyku apnesendromlu hasta grubunda farklı olduğu tespit edildi. Bu hasta grubunda daha ciddi düzeylerde görülen hipoksinin beyin sapına olan etkisinin bu duruma neden olabileceği düşünüldü.

Anahtar Kelimeler: Obstrüktif uyku apnesendromu, apne-hipopne indeksi, işitsel beyin sapı cevabı, polisomnografi.

\begin{abstract}
Objective: Itwill be researchedtheeffects of hypoxia on theauditorybrainstemresponseforpatientswhohaveobstructivesleepapneasyndrome (OSAS).
\end{abstract}

MaterialandMethods: Theresults of brainstem audiometry werecomparedtothreedifferentpatientgroupsconsisting of 31 personshaving OSAS withthecontrolgroupconsisting of 10 personswiththediagnosis of simplesnoring.

Results: Itwasanalyzedamongthecontrolgroupandthegroups of patients in terms of I,III,V. wavelatenciesandtheirinterpeaklatenciesvalues. Itwasconfirmed not to be differentforthesevalues in thegroupwiththemild OSAS. Whilewavelatency III wasstatisticallyholdup in thegroupwithmoderate OSAS, wavelatencies I,III,Vandinterpeaklatency I-III valueswerealsoholdup in thegroupwith severe OSAS.The rate of period in whichthepatientssleepoxygensaturationbeinglessthan \%80 duringthesleep in the total sleep time wasevaluated. Itwasunderstoodthatthis rate is significantlyhigherforthegroupwith severe OSAS comparedtootherpatientgroups.

Conclusion: Itwasthoughtthatthecochlearnucleusneurons which is generating site of wave III, will be moresensitivetohypoxiathanthegeneratingsites of other waves. Itwasfoundthattheresults of brainstemaudiometryaresignificantlydifferentforthepatientgroupwith severe OSAS. Itwasthoughtthattheeffects of hypoxiato be seenmore severe ratestobrainstem can be causedthissituation in thispatientgroup.

Keywords:Obstructivesleepapneasyndrome, apnea-hypopneaindex, auditorybrainstem response, polisomnography. 


\section{GiRiş}

Obstrüktif uyku apnesendromu (OUAS), 30-60 yaş grubu erkeklerin $1 / 4$ 'ünde bu yaş grubu bayanların ise 1/10'unda görülmektedir(1).Obstrüktif uyku apnesi gelişiminde obezite, ileri yaş, erkek cinsiyet ve genetik faktörler başlıca risk faktörleridir(2). OUAS'ı hastalarda görülen apne ve hipopne atakları nedeniyle oksijen desatürasyonları gelişmektedir. OUAS'ı hastalarda, tekrarlayanhipoksi atakları nedeniyle hipertansiyon, ritim bozuklukları, koroner arter hastalıkları ve konjestif kalp yetersizliği insidansı yüksektir(3).

Koklear ileti için gerekli olan endokoklear potansiyel, aktif transport sistemi ile çalışan $\mathrm{Na-K}$ pompası ile işlev görmektedir. Bazı kimyasal maddeler ve damar oklüzyonu ile oksijen desteğinin kesilmesi neticesinde bu pompanın inhibe edildiği gösterilmiştir. Bu inhibisyon sonucunda endokoklear potansiyelde düşüş olduğu görülmüştür(4).

Beyin Sapı Odyometrisi(ABR), dışarıdan işitsel uyaranların verilmesine yanıt olarak VIII. kranial sinir ile birlikte beyin sapı içerisindeki nöral merkez ve yolların ortaklaşa oluşturdukları elektriksel aktiviteyi göstermektedir. İşitme eşiklerinin ve işitmenin periferden santrale kadar uzanan yol boyunca oluşan patolojilerinin belirlenmesinde objektif birtanı yöntemidir $(5,6)$.

ABR dalgalarından; I. dalga, VIII. sinirin ekstrakranial parçasından, II. dalga ise VIII. sinirin intrakranial parçasından kaynaklanmaktadır. Koklearnukleusta bulunan nöronlar tarafindan III. dalga meydana getirilirken, IV. dalganın superioroliverkompleks'teki 3. sıra nöronların etkisi ile oluştuğu düşünülmektedir. Dalga $V$ oluşumunun laterallemniskus ve inferiorkollikulus'taki aktivite ile ilişkili olabileceği belirtilmektedir. Altıncı ve VII. dalga kaynaklarının büyük olasılıkla inferiorkollikulus olduğu düşünülmektedir(7).

$A B R^{\prime}$ de bazı parametreler analiz edilir. Bunlar; dalga morfolojisi, I, III ve V. dalga latansı ve amplütüd'ü, I-III, I-V ve III-V interpiklatansları (IPL), kulaklar arası V. dalga latansı ve I-V IPL farklılığı ölçümleridir. Klinikte en yaygın olarak dalga latans ve IPL ölçümleri kullanılır(8).

ABR ölçümünü etkileyen bireye ait faktörleri, patolojik olan ve patolojik olmayan şeklinde iki başlık altında inceleyebiliriz. Iletim tipi işitme kaybı, koklear işitme kaybı, 8. sinir disfonksiyonu, beyin sapı disfonksiyonu ve serebraldisfonksiyon başlıca bireye ait patolojik olan faktörlerdir(9-11). Yaş, cinsiyet, vücut Isısı ve sedatizan bazı ilaçların kullanımı patolojik olmayan ABR sonucunu etkileyen bireye ait faktörlerdir(12).

Deneysel olarak oluşturulan hipoksik ortamlarda yapılan çalışmalarda, insan ve hayvanlardan elde edilen ABR tetkiklerinde dalgalatanslarında uzama, dalga amplütüdlerinde morfolojik bozukluklar olduğu kayıt edilmiştir(13,14).

Bu çalışmanın amacı, OUAS'ı hastalarda meydana gelenhipoksi durumlarının işitsel beyin sapı cevabı üzerine olan etkilerinin araştrıımasıdır.

\section{GEREÇ ve YÖNTEM}

Bu çalışma, Proje Yönetim Ofisi tarafindan desteklenmiştir. Çalışma için, yerel etik kurul onayı alındıktan sonra Kulak-Burun-Boğaz kliniğine horlama şikayetiyle başvurmuş ve OUAS şüphesiyle polisomnografi (PSG) yapılmış 55 hasta ile görüşüldü. Hastalardan aydınlatılmış onam formu alındıktan sonra ayrıntılı kulak-burun-boğaz muayenesi yapıldı. Bilateral kulak zarı normal olan, aktif bir üst solunum yolu ve otolojikenfeksiyonu saptanmayan hastalara saf ses eşik ortalaması tespiti, konuşmayı ayırt etme skoru tayini ve immitansmetrik incelemeler yapıldı. Saf ses eşik ortalaması bilateral normal sınırlarda olan (0-20 dB.)(15), bilateral konuşmayı ayırt etme skoru \%90'ın üzerinde olan, immitansmetrik incelemelerindebilateralTip A timpanogram vebilateralipsilateral akustik refleksleri elde edilen 41 kişi çalışmaya dahil edildi. Bu kriterlere uymayan 14 kişi çalışmadan çıkartıldı.

Kontrol grubu, daha önce PSG yapılmış olan bu 41 kişi içerisinden Amerikan Uyku Derneğinin yapmış olduğu sınıflandırmaya göre, AHI değeri 5 'in altında olan 10 kişiden oluşturuldu. Geriye kalan 31 hasta yine aynı sınıflandırmaya göre $\mathrm{AHI}$ değerine göre hafif, orta ve şiddetli OUAS'lı gruplar olmak üzere 3 ayrı gruba ayrıldı (Tablo 1).

Kontrol grubu ve hasta gruplarını oluşturan tüm bireylere işitsel beyin sapı cevaplarının değerlendirilmesi amacıyla ABR tetkiki yapıldı. ABR incelemesi ses izolasyonu sağlanmış özel bir odada, GSI Audera marka ABR cihazı ile yapıldı. ABR tetkiki yapılırken aktif elektrot alın bölgesine, topraklama elektrodu iki kaş arasına, 
Tablo 1: Oluşturulan gruplar ve demografik bilgileri.

\begin{tabular}{lccc}
\hline Gruplar & AHI & Hasta sayısı & Yaş ortalaması \\
\hline Kontrol Grubu & $<5$ & 10 (7 erkek, 3 kadın) & $46.2 \pm 6.534$ \\
Hasta Grubu 1 (Hafif) & $5-20$ & 12 (9 erkek, 3 kadın) & $46.6 \pm 8.234$ \\
Hasta Grubu $\mathbf{2}$ (Orta) & $20-40$ & 10 (7 erkek, 3 kadın) & $45.6 \pm 6.193$ \\
Hasta Grubu 3 (Şiddetli) & $>40$ & 9 (7 erkek, 2 kadın) & $48.7 \pm 5.012$ \\
\hline
\end{tabular}

referans elektrotlardan biri sol mastoidapeks diğeri sağ mastoidapeks üzerine yerleştirildi. Tüm elektrotların empedans değerlerinin 5 ohm'un altında olmasına dikkat edildi. Stimuluslar70dB. şiddetinde, tekrar oranı $33.1 /$ sn olacak şekilde verildi ve $150-3000 \mathrm{~Hz}$ band-passfiltrasyonu uygulandı. Stimulus olarak klik ses uyaranı, uyaran polaritesi olarak da rarefaction polarite kullanıldı. Elde edilen verilerden I, III, V. dalgaların latansları ile I-III IPL, III-V IPL ve I-V IPL değerleri tespit edildi.

İstatistiksel değerlendirmede normal dağılım gösteren parametrelerin gruplar arası karşılaştırmalarında Student's t-test, normal dağılım göstermeyen parametrelerin gruplar arası karşılaştırmalarında ise Man-Whitney $U$ testi kullanıldı. Sonuçlar $\% 95^{\prime}$ lik güven aralı̆ı̆ında, ortalama ve standart sapma ( \pm ) olarak verildi. Bu değerlendirmeler neticesinde 0.05 'den küçük olan $p$ değerleri istatistiksel olarak anlamlı kabul edildi.

\section{BULGULAR}

Kontrol grubu ile OUAS'lı hasta grupları arasında, yaş ve cinsiyet dağılımı açısından yapılan istatistiksel analiz sonucunda anlamlı farklııı olmadığı tespit edildi $(p>0.05)$. Kontrol grubundaki ve hasta gruplarındaki toplam 41 kişiye ait olan 82 kulakta yapılan ABR tetkikleri kayıt edildi. Kontrol grubu ile OUAS'।ı hasta gruplaII arasında I, III, V. dalga latans ve IPL değerleri istatistiksel olarak analiz edildi (Tablo 2,Tablo 3).

Kontrol grubu ile hafif OUAS'I grup arasında yapılan değerlendirmede, I., III., V. dalga latans ve I-III IPL, III-V IPL, I-V IPL değerleri arasında istatistiksel olarak anlamlı farklılık olmadığı tespit edildi( $p>0.05)$.
Kontrol grubu ile orta OUAS'lı grup arasında yapılan değerlendirmede, I., V. dalga latans ve I-III IPL, III-V IPL, I-V IPL değerleri arasında istatistiksel olarak anlamI farklılık bulunmazken ( $p>0.05$ ), III. dalga latansının orta OUAS'lı grupta anlamlı derecede gecikmiş olduğu saptandı $(p<0.05)$.

Kontrol grubu ile şiddetli OUAS'।ı grup arasında yapılan değerlendirmede, I., III., V. dalga latans ve I-III IPL değerleri arasında istatistiksel olarak anlamlı farklılık saptanırken ( $p<0.05$ ), III-V IPL ve I-V IPL değerleri arasında anlamlı bir değişikliğin olmadığı görüldü ( $p>0.05)$.

Hasta gruplarının yapılan PSG tetkiklerinden elde edilen veriler incelendiğinde; tüm hastaların ortalama uyku sürelerinin $284.22 \pm 56.691 \mathrm{dk}$. olduğu saptandı. Hastaların uyku sırasındaki yaşadıkları oksijen satürasyonlarının $\% 80$ 'in altına düştüğü süre ve bu sürenin uyku süresine olan oranı incelendi. Bu değerlendirme neticesinde, hafif OUAS'lı grup ile orta OUAS'lı grup arasında istatistiksel olarak anlamlı farklılık saptanmadı ( $p>0.05)$. Hafif OUAS'ı grup ile şiddetli OUAS'lı grup ve orta OUAS'।ı grup ile şiddetli OUAS'। grup arasındaki farkın istatistiksel olarak anlamlı olduğu tespit edildi $(p<0.001)$ (Tablo 4).

\section{TARTIŞMA}

OUASpatofizyolojisiniaraştırmak ve hipoksinin işitme fizyolojisi üzerine olan etkilerinin araştrılması amacıyla çeşitli deneysel ve klinik çalışmalar yapılmıştır.

Hildesheimerve ark.'nın yaptıkları çalışmada, hipoksik kan transfüzyonu ile ratlardahipoksi oluşturulmuştur. Hipoksi öncesi ve sonrasında ölçülen koklear aksiyon potansiyeli eşikleri, aksiyon potansiyeli amplütüd değerleri arasında istatistiksel olarak anlamlı derecede 
Tablo 2: Gruplara ait dalgalatans değerleri.

\begin{tabular}{lccc}
\hline Gruplar (kulak sayısı) & $\begin{array}{c}\text { I. dalga latans } \\
\text { Ort. } \pm \text { ss }\end{array}$ & $\begin{array}{c}\text { III.dalgalatans } \\
\text { Ort. } \pm \text { ss }\end{array}$ & $\begin{array}{c}\text { V. dalga latans } \\
\text { Ort. } \pm \text { ss }\end{array}$ \\
\hline Kontrol Grubu (20) & $1.843 \pm 0.124$ & $3.899 \pm 0.173$ & $6.062 \pm 0.299$ \\
Hasta Grubu 1 (Hafif) (24) & $1.850 \pm 0.083$ & $3.976 \pm 0.141$ & $6.135 \pm 0.161$ \\
& $(p>0.05)$ & $(p>0.05)$ & $(p>0.05)$ \\
Hasta Grubu 2 (Orta) (20) & $1.910 \pm 0.985$ & $4.035 \pm 0.187$ & $(p<0.05)$ \\
Hasta Grubu 3 (Şiddetli) (18) & $(p>0.05)$ & $4.125 \pm 0.193$ & $(p>0.05)$ \\
& $1.959 \pm 0.108$ & $(p<0.05)$ & $6.377 \pm 0.366$ \\
\end{tabular}

Tablo 3: Gruplara ait dalgalar arası latans(IPL) değerleri.

\begin{tabular}{lccc}
\hline $\begin{array}{l}\text { Gruplar } \\
\text { (kulak sayısı) }\end{array}$ & $\begin{array}{l}\text { I-III IPL } \\
\text { Ort. } \pm \text { ss }\end{array}$ & $\begin{array}{l}\text { III-V IPL } \\
\text { Ort. } \pm \text { ss }\end{array}$ & $\begin{array}{c}\text { I-V IPL } \\
\text { Ort. } \pm \text { ss }\end{array}$ \\
\hline Kontrol Grubu (20) & $2.055 \pm 0.139$ & $2.162 \pm 0.277$ & $4.217 \pm 0.293$ \\
Hasta Grubu 1 (Hafif) (24) & $2.122 \pm 0.134$ & $2.158 \pm 0.170$ & $4.285 \pm 0.186$ \\
& $(p>0.05)$ & $(p>0.05)$ & $(p>0.05)$ \\
Hasta Grubu 2 (Orta) (20) & $2.121 \pm 0.200$ & $2.091 \pm 0.226$ & $4.213 \pm 0.255$ \\
& $(p>0.05)$ & $(p>0.05)$ & $(p>0.05)$ \\
Hasta Grubu 3 (Şiddetli) (18) & $2.166 \pm 0.172$ & $2.256 \pm 0329$ & $4.422 \pm 0331$ \\
\hline
\end{tabular}

Tablo 4: Hasta gruplarına ait uyku sırasındaki hipoksi süreleri.

\begin{tabular}{lccc}
\hline Gruplar & O $_{2}$ Sat< \%80 uyku süresi (dk) & $\begin{array}{c}\text { O Sat< \%80 uyku süresi/ } \\
\text { Toplam uyku süresi (\%) }\end{array}$ & $p$ değeri \\
\hline Hafif & $0.050 \pm 0.116$ & $0.016 \pm 0.038$ & $>0.05$ \\
Orta & $0.410 \pm 1.296$ & $0.130 \pm 0.411$ & \\
Hafif & $0.050 \pm 0.116$ & $0.016 \pm 0.038$ & $<0.001$ \\
Şiddetli & $22.033 \pm 26.403$ & $8.011 \pm 9.768$ & $<0.001$ \\
Orta & $0.410 \pm 1.296$ & $0.130 \pm 0.411$ & \\
Şiddetli & $22.033 \pm 26.403$ & $8.011 \pm 9.768$ & \\
\hline
\end{tabular}

farklılık olduğu gösterilmiştir(16).Haupt ve ark.'nın yaptıkları çalışmada, domuzlara 1 saate kadar $\% 8$ $\mathrm{O}_{2}$ içeren nitrojen gaz karışımı solutularak hipoksi oluşturulmuştur. Hipoksi esnasında yapılan ABR tetkiklerinde, dalga amplütüd ölçümlerinin 30. dakikada \%79 değerine, 60. dakikada \%75 değerine kadar azaldığı gözlenmiştir(14). Carlile ve ark. yaptıkları çalışmada, 6 gönüllü bireye oksijen ve nitrojen gaz karışımı solutarak 30 dakika kadar süren hipoksi oluşturmuşlardır. Bu hipoksik süreç sırasında alınan ABR kayıtları sonucunda dalga $\mathrm{V}$ latansında belirgin bir uzama olduğu gösterilmiştir(13).

Karnazeve ark.'nın yaptıkları çalışmada, uyku apnesendromlu 18 hastanın ABR ölçümlerinde I-V IPL sonuçları değerlendirilmiştir. Uyku apnesendromlu sadece bir hastada I-V IPL değerinin anlamlı derece- 
de uzamış olduğunu saptamışlardır(17). Liu ve ark. yaptıkları çalışmada, 37 şiddetliOUAS'।ı hasta ile 20 kişiden oluşan kontrol grubunun ABR sonuçlarını karşılaştırmışlardır. Hasta grubunda, dalga I latansının anlamlı derecede uzamış olduğunu ve I-III IPL'nın kısaldığını saptamışlardır(18). Ni,200UAS'lı hasta ile yaptı̆̆ çalışmada, ABR tetkik sonuçlarını değerlendirmiştir. OUAS'Iıhastalarda dalga I, dalga V latanslarının ve III-V IPL'nınanlamlı derecede uzamış olduğunu, I-III IPL'nın ise kısaldığını saptamıştır(19). Muchnik ve ark.'nın yaptıkları çalışmada, OUAS'lı 79 hasta ile kontrol grubunun ABR tetkik sonuçları karşılaştrıımıştır. Hafif, orta, şiddetli OUAS'I gruplardaki dalga I, dalga III ve dalga $\checkmark$ latansdeğerlerinin kontrol grubuna göre anlamlı derecede uzamış olduğunu belirtmişlerdir. Aynı zamanda orta ve şiddetli OUAS'lı gruptaki I-III IPL, I-V IPL değerlerinin kontrol grubuna göre anlamlı derecede uzamış olduğunu tespit etmişlerdir(20).Casale ve ark.'nın 39 hasta üzerinde yaptıkları çalışmada, şiddetli OUAS grubu ile kontrol grubunun odyolojik tetkikleri karşılaştırılmıştır. OUAS'lı grupta saf ses eşik ortalamasının anlamlı derecede daha yüksek olduğu görülmüştür. ABR sonuçlarında ise dalga I, dalga III, dalga Vlatansları ve I-III IPL, III-V IPL, I-V IPL değerlerinin kontrol grubuna göre anlamlı düzeyde uzamış olduğunu saptamışlardır(21).

Uyku-uyanıklık durumu ABR sonuçlarını etkilememektedir(12).Mosko ve ark. AltiOUAS'lıhasta ile yaptıkları çalışmada, hastalar uyurken ve uyanıkken elde ettikleri $A B R$ tetkik sonuçlarını karşılaştırmışlardır. $\mathrm{Bu}$ değerlendirme sonucunda, tüm dalga latansları arasında anlamlı derecede farklıık olmadığını tespit etmişlerdir(22).Bu bilgiler doğrultusunda, çalışmamızda ABR tetkiki hastalar uyanıkken yapılmıştır.

Bizim çalışmamızın literatürdeki bu çalışmalardan en önemli farkı; ABR sonuçlarını etkileyebilecek olan gruplar arasındaki yaş, cinsiyet farklılı̆ının olmaması ve işitme azlığı olan bireylerin çalışma dışında tutulmuş olmasıdır.

Çalışmamızda, orta OUAS'ı grupta etkilenen tek parametre dalga III latansıdır. Aynı zamanda şiddetli OUAS'Iı grupta ABR dalgaları arasında en belirgin uzamanın dalga IIIlatansında olduğugörülmüştür. Dalga III latansındaki bu belirgin değişikliğin nedeni olarak, bu dalganın kaynağı olan koklearnukleusnöronlarının diğer ABR dalga kaynaklarına göre hipoksiye daha fazla duyarlılığı olabileceği düşünüldü. Hastaların PSG tetkiklerinde saptananhipoksinin, şiddetli OUAS'lı grupta diğer hasta gruplarına göre belirgin derecede daha ciddi seviyelerde olduğu tespit edildi. ABR değişikliklerinin özellikle şiddetli OUAS'lı grupta gözlenmesinin bu hipoksik durumun beyin sapına olan etkilerinden kaynaklanabileceği düşünüldü.

\section{KAYNAKLAR}

1. Moyer CA, Sonnad SS, Garetz SL, et al.Quality of life in obstructivesleepapnea: a systematicreview of theliterature. SleepMedicine2001;2(6):477-91.

2.Casale $M$, Vesperini $E$, Potena $M$, et al. Is obstructivesleepapneasyndrome a risk factorforauditorypathway? SleepBreath 2011;16(2):517-21.

3. Franklin KA, Sahlin C, Nilsson J.B, etal.Sleepapneaandnocturnalangina. TheLancet 1995;345(8957):1085-7.

4.Gafni M, Sohmer H. Intermediateendocochlearpotentiallevelsinducedbyhypoxia. ActaOtolaryngol 1976; 82(5-6):354-8.

5. Jiang ZD. Maturation of peripheralandbrainstemauditoryfunction in thefirstyearfollowingperinatalasphyxia: a longitudinalstudy. J Speech LangHearRes 1998;41(1):83-93.

6.Lary S, Briassoulis G, de Vries L, et al. Hearingthreshold in pretermandterminfantsbyauditorybrainstemresponse. J Pediatr 1985;107(4):593-9.

7.Wilkinson AR, Jiang Ze D. Brainstemauditoryevokedresponse in neonatalneurology. Seminars in Fetal\&NeonatalMedicine2006;11(6):444-51.

8.Esteves MCBN, Dell' AringaAHB, Arruda GV, et al. Brainstemevokedresponseaudiometry in normal hearingsubjects. Braz J Otorhinolaryngol 2009;75(3):420-5.

9.Hall JW(Editor). Handbook of auditoryevokedresponses. Boston: Allynand Bacon, 1992.

10.Hall JW III, Mueller HG III(Editors). Audiologists'deskreference. San Diego-London: SingularThomson Learning, 1997:319-89.

11.Katz J(Editor). Handbok of clinicalaudiology. In: Don M, Kwong B. Auditorybrainstemresponse: differ- 
entialdiagnosis. 5thEdition, Philadelphia: Lippincott Williams \&Wilkins, 2002:274-97.

12.RoeserRJ, Valente $M$, Hosford-Dunn H(Editors). Audiologydiagnosis. In: Arnold SA. Theauditorybrainstemresponse. 2th Edition, New York: ThiemeMedicalPublishers, 2007:426-43.

13.Carlıle S, Bascom DA, Paterson DJ. Theeffect of acutehypoxia on thelatency of thehumanauditorybrainstemevokedresponse. ActaOtolaryngol 1992;112(6):939-45.

14. Haupt $\mathrm{H}$, Scheibe $\mathrm{F}$, Ludwig $\mathrm{C}$. Changes in cochlearoxygenation, microcirculationandauditoryfunctionduringprolonged general hypoxia. EurArchOtorhinolaryngol 1993;250(7):396-400.

15.Çakır N(Editör). Otolaringoloji ve baş-boyun cerrahisi. İşitme fizyolojisi. 2'nci Baskı,İstanbul: Nobel Tıp Kitapevleri Ltd. Şti, 1999:12-4.

16. Hıldesheımer M, Muchnık H, Rubınsteın M.Cochlearhypoxiaandthecompoundactionpotentials.Laryngoscope 1988;98(5):557-60.
17.Karnaze D, Gott P, Mitchell F, et al.Brainstemauditoryevokedpotentialsare normal in idiopathicsleepapnea. AnnNeurol 1984;15(4):406.

18.Liu D, Chen Q, Huang Z, et al. Auditorybrainstemresponse in severe obstructivesleepapnea-hypopneasyndromechildren. LinChuang Er Bi Yan HouKeZaZhi 2005;19(19):868-70.

19.Ni D. Auditorybrainstemresponse in obstructivesleepapneasyndrome. ZhonghuaEr Bi Yan HouKe ZaZhi1991;26(5):284-6.

20.Muchnik C, Rubel Y, Zohar Y, et al. Auditorybrainstemresponse in obstructivesleepapneapatients.J Basic ClinPhysiolPharmacol 1995;6(2):139-48.

21.Casale $M$, Vesperini E, Potena $M$, et al. Is obstructivesleepapneasyndrome a risk factorforauditorypathway? Area of Otolaryngology 2012;16(2):413-7.

22. Mosko SS, Pierce S, Holowach J, et al. Normal brainstemauditoryevokedpotentialsrecordedsleepapneicsduringwakingand as a function of arterialoxygensaturationduringsleep. Electroencephalogr.ClinNeurophysiol1981;51(5):477-82. 